\title{
Quantitative Analysis of Platelet Size by Atomic Force Microscopy
}

Harry J. Ploehn* ${ }^{1}$, Chunyan Liu ${ }^{1}$, Wally A. Scrivens ${ }^{2}$, and Hans-Conrad zur Loye ${ }^{2}$

\section{Supporting Information}

Table S1. Effective MMT particle size as a function of sonication time.

\begin{tabular}{|l|l|l|l|l|l|l|l|l|}
\hline Time (min) & 0 & 20 & 40 & 60 & 80 & 100 & 120 & 140 \\
\hline Particle size (nm) & 413 & 402 & 399 & 401 & 399 & 415.6 & 396.4 & 403 \\
\hline Polydispersity (\%) & 26.8 & 26.2 & 25.4 & 27.5 & 24.4 & 24.2 & 25.1 & 25.6 \\
\hline
\end{tabular}

Table S2. Values of MMT concentration and effective spherical particle diameter as functions of centrifuge rotational speed and centrifugal acceleration.

\begin{tabular}{|l|c|c|c|c|c|c|c|c|c|}
\hline Rotational Speed (rpm) & 0 & 500 & 1000 & 2000 & 3000 & 4000 & 5000 & 6000 & 7000 \\
\hline Centrifuge acceleration (g's) & 0 & 31 & 125 & 501 & 1127 & 2003 & 3130 & 4507 & 6135 \\
\hline Concentration (wt\%) & 0.87 & 0.84 & 0.83 & 0.78 & 0.72 & 0.69 & 0.65 & 0.56 & 0.51 \\
\hline Particle size (nm) & 403.4 & 403 & 398.7 & 336.4 & 307 & 292.4 & 279.5 & 269.8 & 265.1 \\
\hline Polydispersity (\%) & 25.5 & 26.6 & 27.4 & 23.4 & 21.8 & 24.2 & 23.0 & 21.0 & 23.1 \\
\hline
\end{tabular}

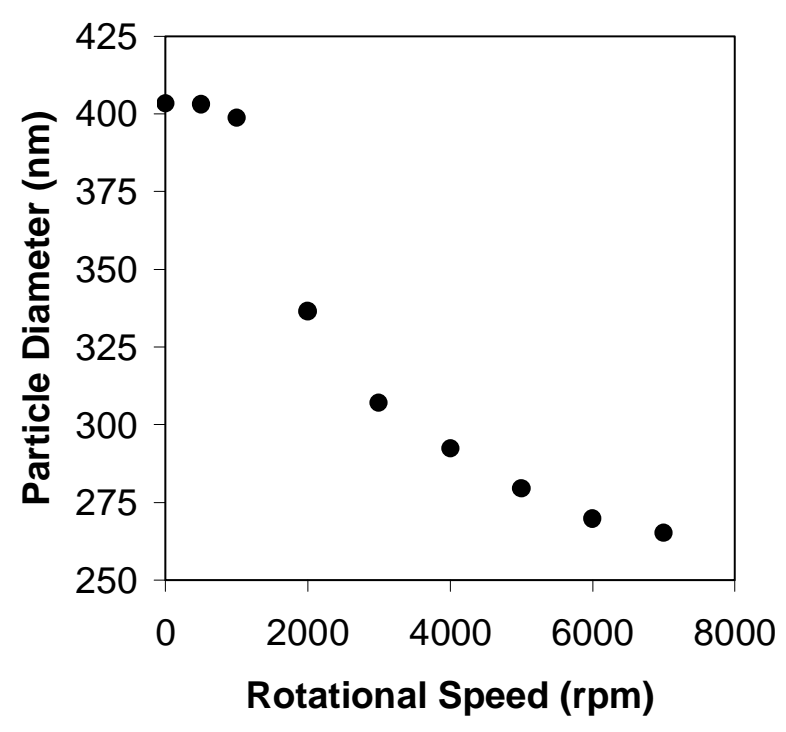

Figure S1. MMT effective spherical particle diameter as a function of centrifuge rotational speed. 


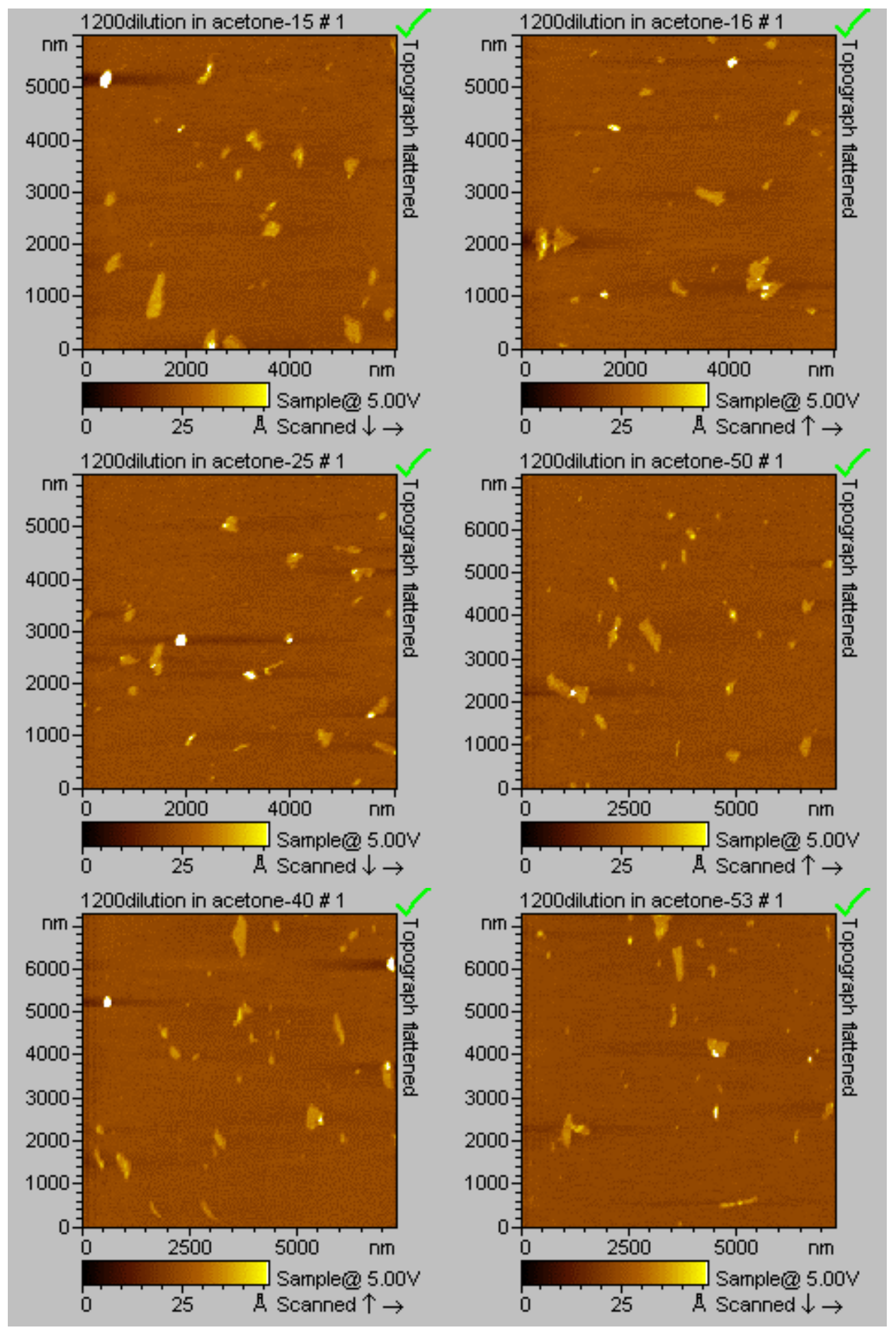

Figure S2. Typical AFM images of a MMT suspension diluted 1200-fold in acetone. 


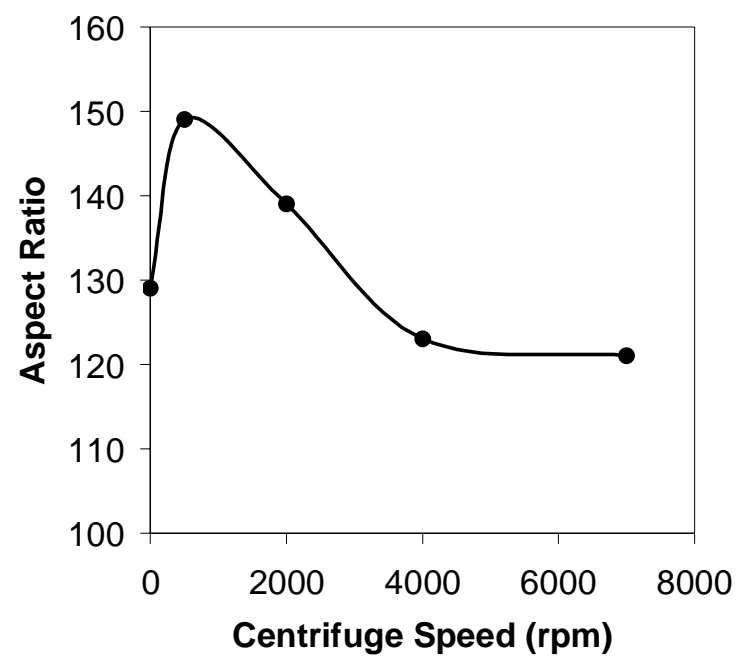

Figure S3. Average aspect ratio of MMT particles remaining in suspension as a function of centrifuge rotational speed. 


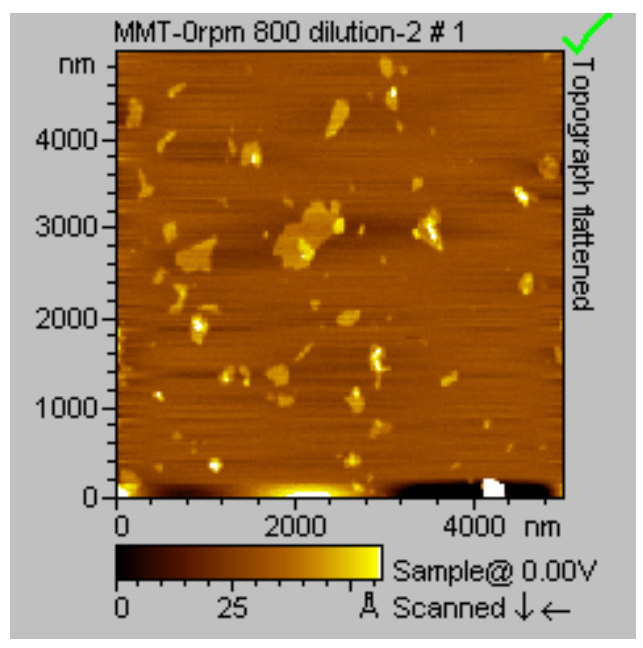

(a) $0 \mathrm{rpm}$

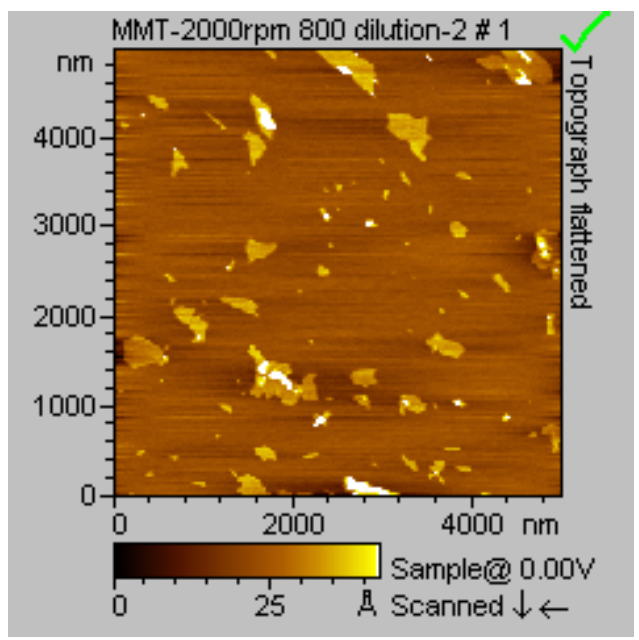

(c) $2000 \mathrm{rpm}$

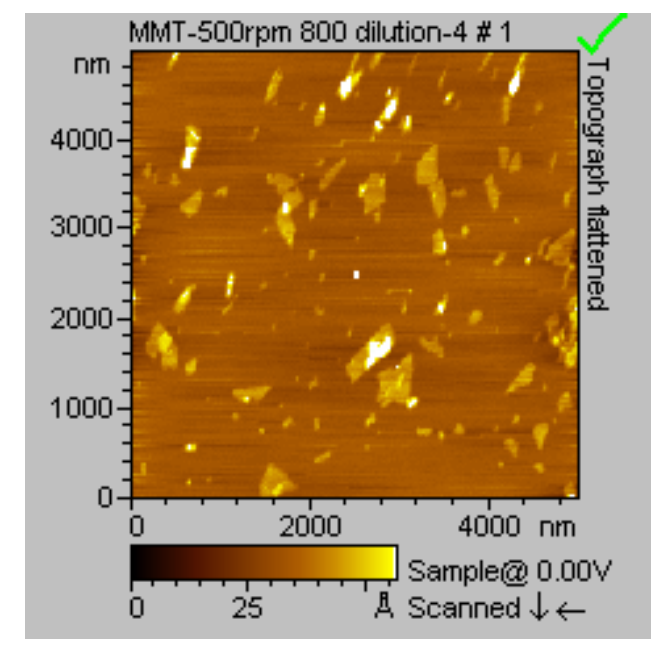

(b) $500 \mathrm{rpm}$

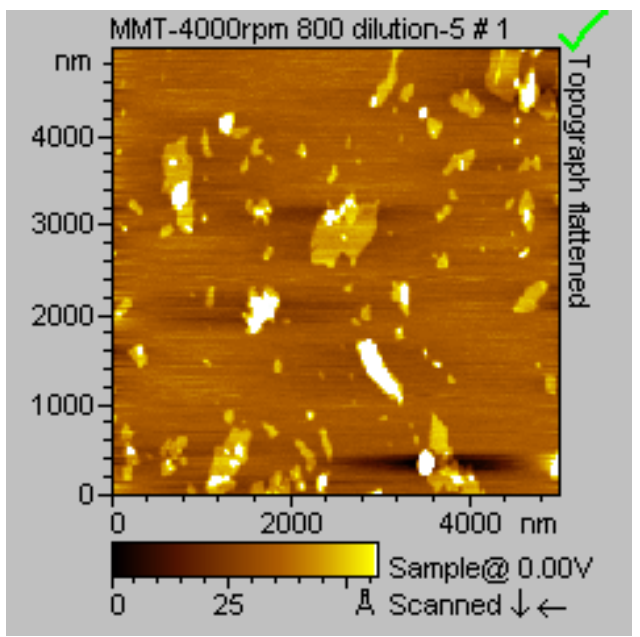

(d) $4000 \mathrm{rpm}$

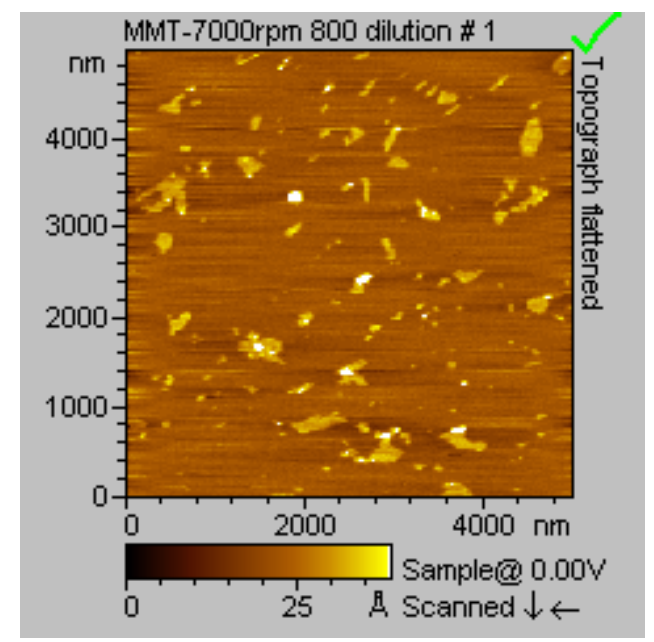

(e) $7000 \mathrm{rpm}$

Figure S4. Typical AFM images of MMT suspensions centrifuged at various rotational speeds. 